\title{
A System Model for Analyzing and Accumulating Construction Work Crew's Productivity Data Using Image Processing Technologies
}

\author{
Chankyu Lee ${ }^{1}$, Jaeho Son ${ }^{2}$ and Seunghyun Lee ${ }^{*^{3}}$ \\ ${ }^{1}$ Graduate Student, Graduate School of Architectural Engineering, Hongik University, Korea \\ ${ }^{2}$ Professor, School of Architectural Engineering, Hongik University, Korea \\ ${ }^{3}$ Associate Professor, School of Architectural Engineering, Hongik University, Korea
}

\begin{abstract}
Recently, several studies pertaining to the measurement and analysis of construction productivity data have been attempted using image-processing technology. However, these studies have mainly focused on the recognition of individual labor and the materials at construction job sites. This research develops a new system model, which automatically analyzes and accumulates a construction work crew's productivity data using image processing technologies. It includes the three modules as follows: 1) the acquisition of a construction job site's video images and calibration for their recognition, 2) measurement and analysis of the construction work crew's productivity data, and 3) creation and utilization of a productivity database. New algorithms are proposed for each module. YCbCr settings are used to develop a calibration algorithm for improving the rate of recognition. Work sampling and video editing are used to develop an algorithm for measuring and analyzing the crew's productivity data. Then, an algorithm for productivity data accumulation and its utilization is proposed by utilizing the integration of the BIM Model. This developed system model is applied to a real construction site and validates its feasibility through two case studies.
\end{abstract}

Keywords: automatic data acquisition; construction work crew's productivity; image processing technology; system model; BIM integration

\section{Introduction}

\subsection{The Background and Purpose of Study}

Productivity in the construction industry is used as an indicator of the efficiency and consistency of a construction organization (Kim, 2008). As a result of rising interest in construction productivity, there have been several studies pertaining to the effective measurement, analysis, and storage of productivity data. However, these previous studies lack employment of a systematic and cohesive process, which leads to an insufficient and impractical use of the data (Woo, 2007).

To solve this problem, there have been some studies that have focused on productivity data acquisition and data analysis based on information technology. Yet still, the efficiency of measurement and credibility of the collected data have not been well established.

\footnotetext{
*Contact Author: Seunghyun Lee, Associate Professor, School of Architectural Engineering, Hongik University, A410, 2639 Sejong-ro, Jochiwon-eup,

Sejong, 339-701, Korea

Tel: +82-44-860-2213 Fax: +82-44-868-3022

E-mail: slee413@hongik.ac.kr

(Received October 2, 2013 ; accepted July 1, 2014)
}

Similarly, several studies based on image processing technology have been done, but these studies are focused mainly on the recognition of individual labor and the materials at construction job sites. Despite their efforts, these studies were still unable to measure the productivity of the construction work crew's themselves. Thus, this study develops a system model for analyzing and accumulating the productivity data of a work crew on a construction site based upon image processing technology. This developed model is applied to a real construction site and validates its feasibility through two case studies.

\subsection{Scope and Methodology of Research}

The scope of this study is to develop a system model including three modules along with new algorithms for each module.

New algorithms are proposed for the three modules as follows: 1) acquisition of a construction job site's video images and calibration for their recognition, 2) measurement and analysis of the construction work crew's productivity, and 3) creation and utilization of a productivity database. $\mathrm{YCbCr}$ settings were used to develop a calibration algorithm of video images for improving the rate of recognition. Work sampling and video editing were applied to the algorithm for measuring and analyzing the productivity data. Then, 
an algorithm for productivity data accumulation and its utilization was proposed by utilizing the integration of the BIM Model.

The methodology and process of this research that proposes and validates a system model is shown in Fig.1. Research initially began with the analysis of literature reviews to seek the limitations regarding productivity measurement and its utilization with image processing technology. From this, a system model was developed based upon the previous measuring algorithms and an additional three algorithms. The previous algorithms developed by the authors of this study have been modified for measuring the installed work quantity and working hours of construction workers with a higher recognition rate. In addition, the new algorithms have been developed for recognition improvement, measurement and analysis of productivity data, and the creation and utilization of the database integrating BIM model. This developed system model is then applied to an existing construction site to validate its feasibility.

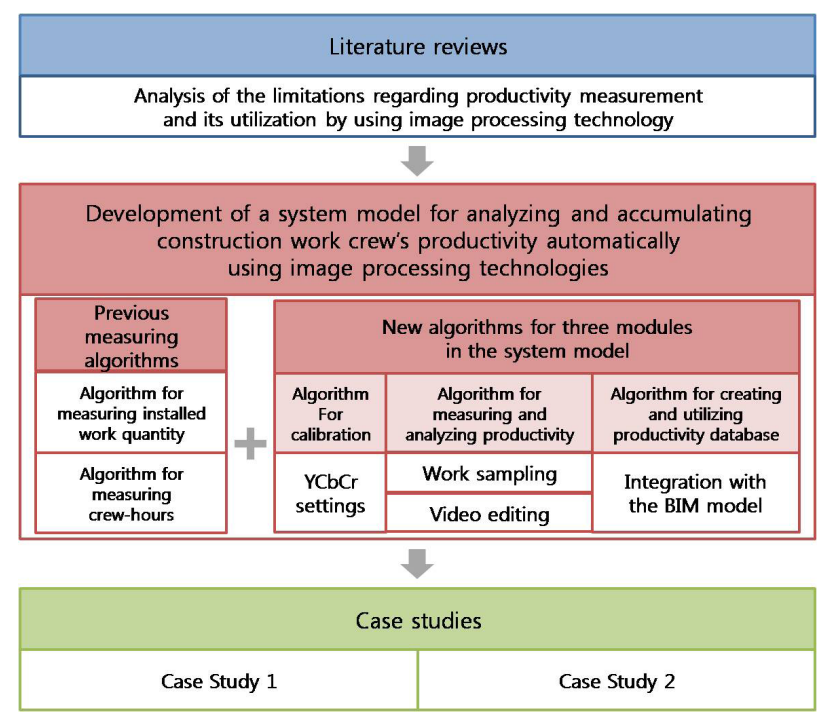

Fig.1. Research Methodology and Process

\section{Literature Review of Relevant Research Works}

Productivity data obtained from the activity level is utilized as the main indicator for efficient construction management. It not only determines the efficiency of construction progress, but also decides crew size and configuration. It can also predict the remaining tasks, which makes the process highly efficient. A systematic analysis on the work performed by construction workers, as well as other related factors on the work, is required for these processes to be accomplished (Lee, 2006).

Image processing technology, one of the latest information technologies, has recently been applied for this purpose. This image processing technology is useful for motion tracking and the recognition of objects, such as the human body or face. When this technology is applied to the construction job site, reliable data can be obtained through an efficient data collection process. This process utilizes an automated system to minimize the efforts of data collection. Thus, this technology can be used in various areas such as material management, construction safety, productivity management, etc.

Therefore, several attempts have been made to apply image processing technology to the construction area. However, most of these studies mainly focused on the recognition of the object. Some of them simply focused on the construction workers and were unable to recognize the different work crews and each of their separate tasks.

In this section, the researches related to the application of image processing technologies in the construction area are reviewed and summarized in terms of productivity data acquisition.

Peddy (2009) extracted human silhouettes using the Background Modeling technique. He proposed a method to recognize the motion of a worker by changing the extracted silhouette into the shape of a skeleton by using a neural network and further image processing technologies. However, this method had its limitations seeing that it could not differentiate the various crews involved in different tasks. Also, he did not establish a system for the measurement of a crew's productivity.

Oh (2011) proposed a prototype model to measure the installed quantity of an aluminum form. The model used Binary, Template Matching, and Histogram Matching in order to measure the installed quantity of an aluminum form derived from work site images. This model recognizes the installed aluminum form by using image processing analysis.

Gong (2011) proposed a method to classify the motions of backhoes and the installers of the aluminum forms on the construction site. This method tracks an object by using the difference between the current frame and its background. The motion of the object is defined by detecting the corner of the object. The method determines which motion is taken by the analysis of real-time video images. However, this method focused more on the differences between the motion and non-motion of an object. It could not measure the productivity of the construction operations.

Lee (2011), one of the authors in this research, measured the number of workers and their working periods. The model uses BGS, Color Histogram, Human Body Structure, and Optical Flow. The model focuses on the recognition of the worker. However, it lacks an automatic measurement of the productivity of the construction crew and does not develop an accumulation method for the measured data. 
Weerasinghe (2012) found the worker by using Kinect, a motion sensing input device, which tracks the safety helmet and shape of a skeleton. The color of the helmet helps to distinguish the workers on a site. This study proposes a method to find the worker's location by using the 3D depth sensor of the Kinect. Despite these innovations, the measurement of the productivity of the crew could still not be obtained.

Escorcia (2012) found the location information of a worker using Kinect. The worker's pose is recognized as a skeleton image. The recognized skeleton image is then classified to a specific task. However, this too only focuses on the recognition of a worker, not the crew.

Park (2012) recognizes moving objects by using BGS, classifies humans using the HOG algorithm, and finds the worker using a Color Histogram. Nonetheless, the HOG algorithm takes a tremendous amount of time to process information and causes a problem in analyzing real-time video image. This method also focuses mainly on the recognition of the worker.

\section{Model Development}

Two previous algorithms related to image processing technology were adopted and modified to develop a newly proposed system model. An algorithm for measuring crew-hours and an algorithm for measuring the installed work quantity were collaboratively modified. The main tasks of developing the new algorithms for the system model proposed are as follows:

1. Since the two previous algorithms recognize the object according to the site condition, they have a limitation in reflecting various site conditions. Thus, the new algorithm for image processing reflects various site conditions and is further modified and developed to enhance and improve the recognition rate.

2. Measuring the crew-hours is basically obtained through the analysis result of video image processing. Measuring the installed work quantity is obtained through the analysis result of the picture image processing. By considering these differences, a new algorithm is proposed to measure and analyze a construction work crew's productivity.

3. An algorithm for creating and utilizing a productivity database is developed based upon integration with BIM models. It can be used to build a productivity database for construction management.

\subsection{Calibration Algorithm for Improving the Recognition} Rate

The new proposed system model analyses the video image file of the job site recorded with a video camera. It collects data through video image processing. Therefore, if the recognition rate is higher, more accurate data can be collected. There are difficulties due to the fact that construction sites can be affected by different work environments such as sunlight, shadows, weather, etc. Thus, in order to collect precise data, the developed system model comes up with a recognition process to reflect those various work environments. The proposed system model classifies various crews with different recognizable colors. The setting of $\mathrm{YCbCr}$ values is used to calibrate the disturbed factors in image processing. $\mathrm{YCbCr}$ is a family of color spaces used as a part of the color image pipeline in video and digital photography systems. Herein, $\mathrm{Y}$ is the luminance component, $\mathrm{Cb}$ is blue chromaticity, and $\mathrm{Cr}$ is red chromaticity (Kekre, 2013). Fig.2. shows a screenshot of how to set the $\mathrm{YCbCr}$ values. The model sets a threshold in order to reduce the noise of the disturbing factors. It helps to enhance the color recognition of safety helmets and safety vests with more clarity. It can then classify the different crews with different colors.

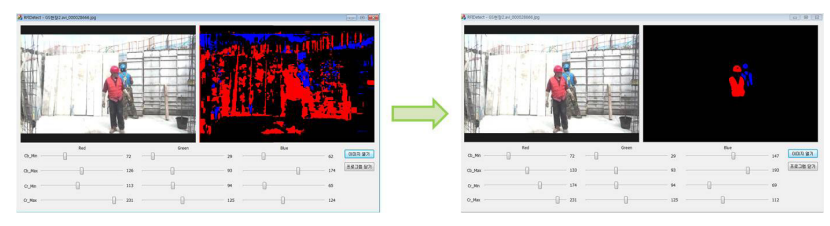

Fig.2. Removing Noise by $\mathrm{YCbCr}$ Settings

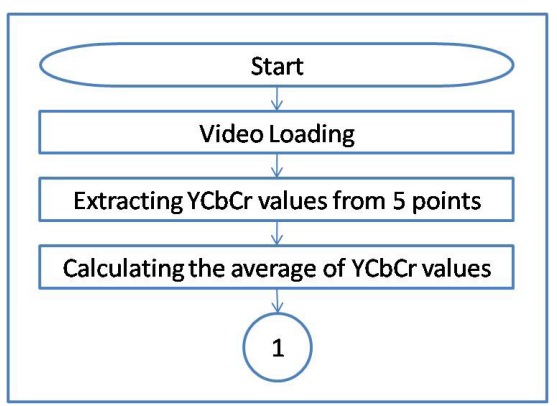

Fig.3. An Algorithm for Calibrating Video Images

Fig.3. shows a calibration algorithm for improving the recognition rate. The recognition rate means the rate of the time that a work crew is recognized with the algorithm for measuring the crew-hours to the work hours of the work crew measured with video analysis. $\mathrm{YCbCr}$ values are extracted from 5 points, which were randomly chosen from the recorded video image. Then the average value of these 5 extracted values is calculated. The average value is set as a threshold value and is input to the system (See (1) in Figs.3. \& 4.). Table 1. shows the code for setting these threshold values. This algorithm helps to reflect the various work environments in the developed system model. It turned out to have increased up to $94.75 \%$ with the utilization of this algorithm. This value is the average recognition rate in the 6 cases. In the results of precedent studies mentioned in the preceding Chapter 2, the recognition rate was about $71 \%$ when the construction workers wearing safety gear were recognized with image processing from the video images. Therefore, the recognition rate of this paper was significantly higher. 
Table 1. The Code for Setting YCbCr Threshold Values

$\mathrm{Cb} \mathrm{dt}=0$;

Cr_ $\mathrm{dt}=0 ; / /$ Variables to temporarily store image value

intnBcbMIN $=140$, nBcbMAX $=193$, nBcrMIN $=69$, $\mathrm{nBcrMAX}=125$;

$/ / \mathrm{nBcbMIN}$ : The minimum $\mathrm{Cb}$ value of the Blue, nBcbMAX : The maximum $\mathrm{Cb}$ value of the Blue, nBcrMIN : The minimum $\mathrm{Cr}$ value of the Blue, nBcrMAX : The maximum $\mathrm{Cr}$ value of the Blue

// Part to determine the Blue's image value if $((\mathrm{nBcbMIN}<=\mathrm{Cb}$ dt $\& \& \mathrm{Cb} d \mathrm{dt}<=\mathrm{nBcbMAX}) \& \&$ $($ nBcrMIN $<=$ Cr_dt $\& \& C r$ d $\mathrm{dt}<=$ nBcrMAX $))$

$\left\{\left(\left(\right.\right.\right.$ uchar* $\left.^{*}\right)($ outputImage->imageData $\left.)\right)[\mathrm{i} *$ outputImage $>$ widthStep $+\mathrm{j} * 3+0]=255 ; / /$ Blue

((uchar*)(outputImage->imageData) $)[\mathrm{i} *$ outputImage $>$ widthStep $+\mathrm{j} * 3+1]=0$; // Green

((uchar*)(outputImage->imageData) $)[i *$ outputImage $>$ widthStep $+\mathrm{j} * 3+2]=0 ; / /$ Red $\}$

\subsection{Algorithm for Measuring and Analyzing Productivity}

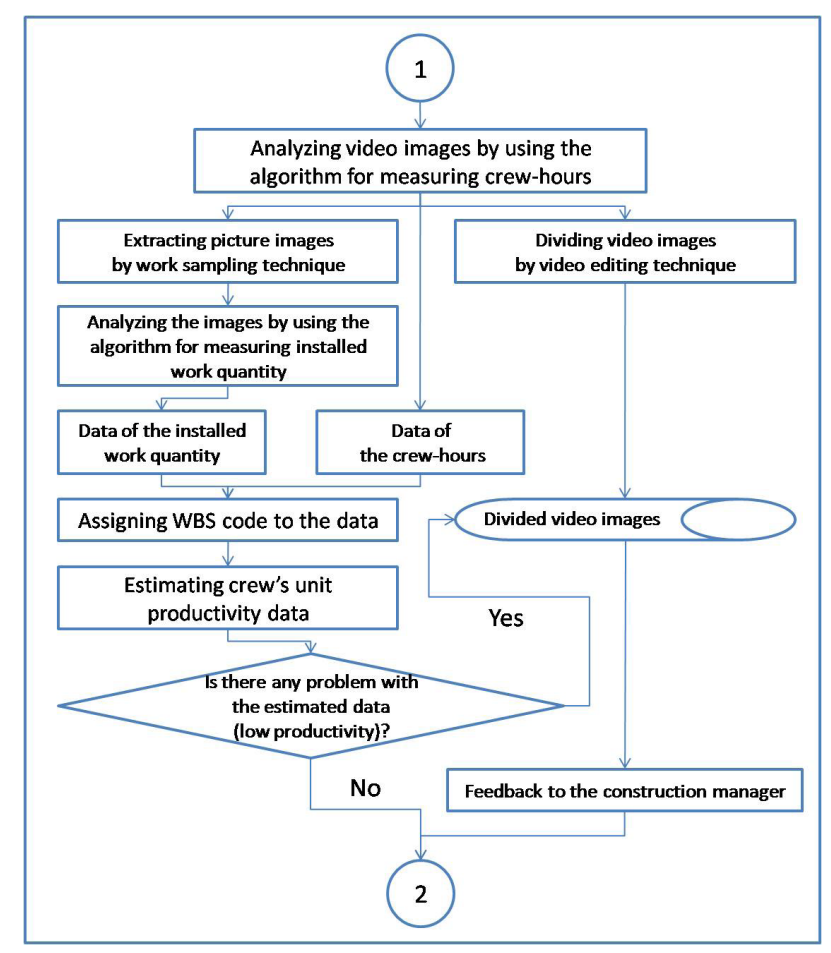

Fig.4. An Algorithm for Measuring and Analyzing a Crew's Productivity

This study suggests an algorithm for measuring and analyzing a construction work crew's productivity along with video image processing as shown in Fig.4.

In this stage, two algorithms previously developed by this research team are utilized and further modified to measure crew-hours and installed work quantities. The threshold of $\mathrm{YCbCr}$ in Fig. 3. is input to the algorithm for measuring crew-hours as previously mentioned. The algorithm for measuring the installed work quantity recognizes objects based on picture images. Therefore, a picture image for measuring installed work quantity must be extracted from the video images of the crew-hours recognized. The scope of this research is limited to the installation of formwork. Measuring the amount of formwork at a particular time is done within a relatively short period. To analyze these tasks within this relatively short period, the work sampling method is applied.

First, the period of measurement is determined. Then, images are continually extracted from the video at every pre-established period in the cycle. The extracted image is then analyzed using the algorithm for the recognition of the installed work quantity and stored in an Excel file format. By using this data and the estimated crew-hours data, the crew's unit productivity data can be calculated for each measurable work unit.

Statistical methods used to handle outliers determine whether the obtained data is adequate. An outlier is an item that appears to deviate markedly from other members of the sample in which it occurs (Ordonez, 2011). It is ideal to remove an outlier from sample data because it may affect decision-making.

However, outliers that arise in the course of construction work are generally detected due to improper performance of workers. In this study, outliers are used as indicators that provide warning signals to the construction manager. Outliers are calculated as shown in the following equation (1).

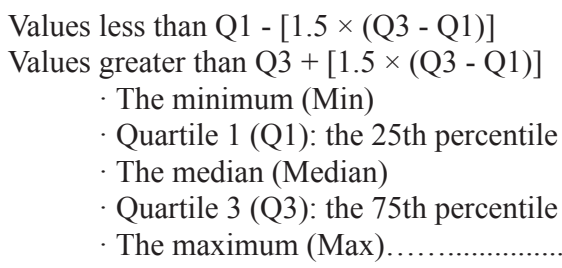

Data outside of this range will be confirmed by the construction manager. The video editing technique is used to store image data, which is checked by the construction manager. According to the measurement cycle of work sampling, the video image of work is divided and then separately stored utilizing the video editing technique.

These stored video images can be used for review purposes when the measured productivity reveals a large difference. For instance, since apartment construction processes are repetitive, the crew's production rate of the apartment unit walls must be constant. If the production rate deviates from the constant production rate, it means there is a problem that the manager must pay attention to. This model shows the divided video images to the construction manager and he/she identifies and solves the problem without having to go to the actual job site.

The productivity data is analyzed and linked with the WBS (Work Breakdown Structure) code created based on the building components. The data is then transferred to the productivity database. 


\subsection{Algorithm for Creating and Utilizing a Productivity Database}

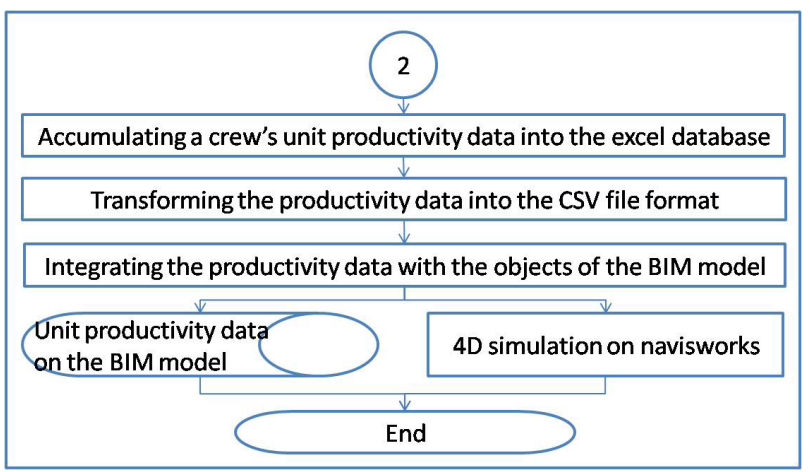

Fig.5. An Algorithm for Creating and Utilizing a Productivity Database

Fig.5. shows an algorithm for creating and utilizing a database by integrating the accumulated productivity data with the BIM Model. BIM is efficient for the integration and management of data production (Park, 2011).

Productivity data must be accumulated in the Excel database first. Then, they should be transformed into a CSV file format in order to be integrated with the objects of the BIM Model. Fig.6. shows the input screenshot for the field selector of Navisworks.

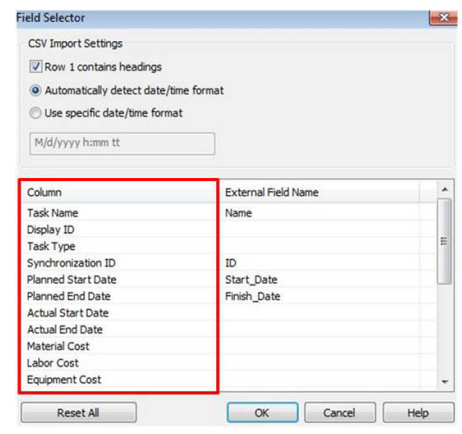

Fig.6. The Field Selector of Navisworks

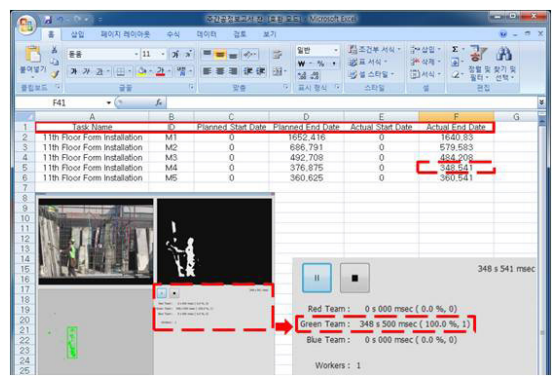

Fig.7. An Example of CSV File Creation

For a smooth integration, each item in the left column of Fig.6. must to be matched to each corresponding item in the first row of the Excel file shown in Fig.7. The accumulated crew-hours data is input to the cell indicating the actual finish date. The start data is input to the cell indicating the actual start date. The Excel file is then saved in the CSV file format.
As illustrated by the right screen shot in Fig.8., the 3D model is opened in Navisworks and the stored CSV file is loaded. Out of the three options of construction, demolition, and temporary, one is selected as shown in the left screen shot. After the linkage of the CSV file and the $3 \mathrm{D}$ model, the productivity data linked with the objects of the BIM model can be used to create a 4D simulation, which helps to predict construction scheduling for management purposes.
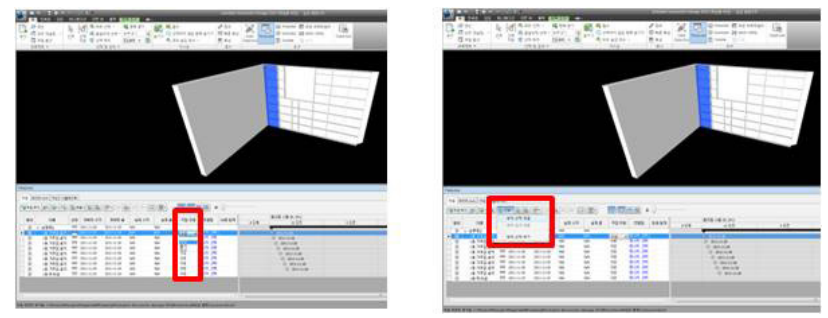

Fig.8. An Illustration of CSV File Linked with Navisworks

\subsection{Overall System Model Developed}

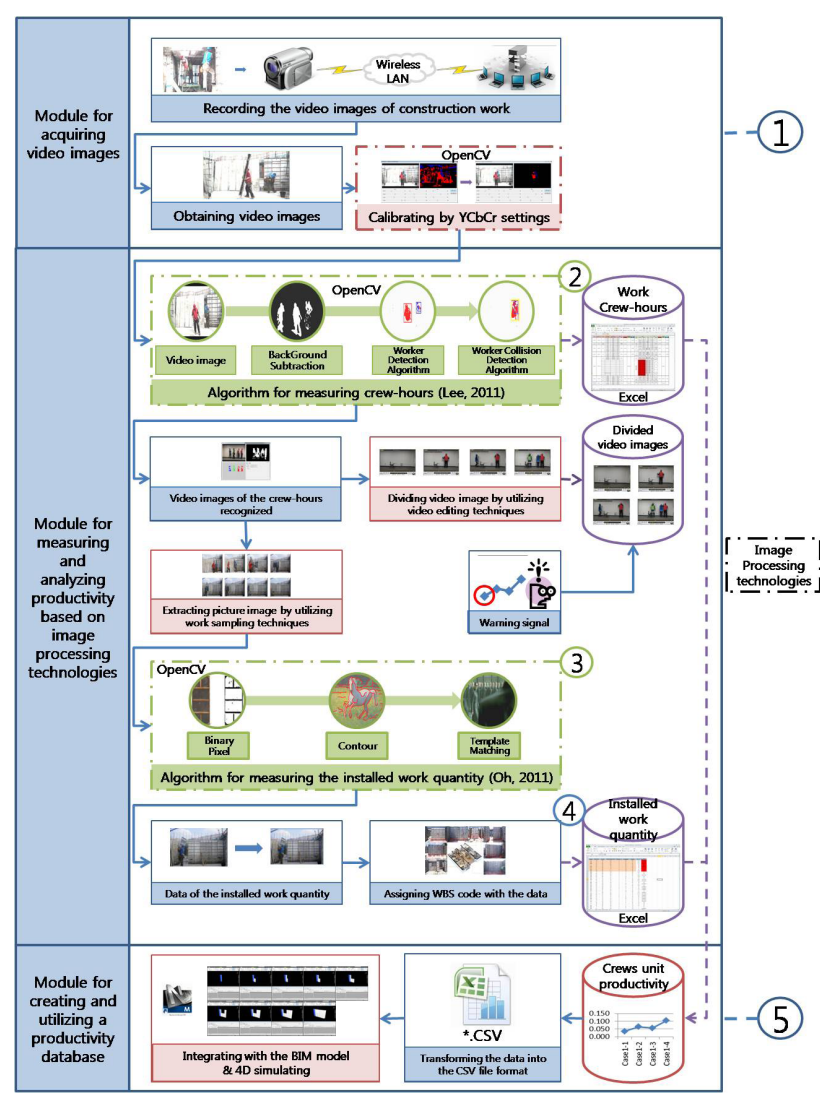

Fig.9. The Overall Design of the Proposed System Model

Fig.9. depicts the overall design of the proposed system model for acquiring a construction work crew's productivity data in this study. The system model has three modules. One collects the work site video images and calibrates $\mathrm{YCbCr}$ values for the improvement of the recognition rate. Another measures and analyzes the productivity of the crew. The last accumulates and uses the crew's unit productivity data by integrating the objects created by BIM tools. 
The location of the camera is an important aspect of the first module (See (1) in Fig.9.) because it collects video images of the job site.

Depending on the size and the conditions of the construction site, there are many variables that complicate the collection of image data. The workers, materials, and equipment frequently move. A blind spot may arise due to the columns and walls of the construction site. For these reasons, the selection of the camera's location is highly important. Therefore, it is ideal to install the minimum number of cameras necessary to avoid blind spots on the construction site.

For this study, a camera was installed at a height of $1.5 \sim 2 \mathrm{~m}$ and a distance of $4 \sim 7 \mathrm{~m}$ from the walls. This was done in order to obtain precise productivity data by maximizing the recognition of installed work quantity.

The colors of safety helmets and vests are used to distinguish various crews on the construction site. Every worker on a construction site must wear safety gear. This is an advantage to image processing because all safety helmets are identical and can therefore be easily recognized.

Workers wear safety helmets and vests of different colors such as red, green, or blue. The installation tasks of the construction sites are then recorded and transferred to the computer using wireless LAN. The image data is input to the module for measuring and analyzing productivity in the developed model. Crewhours are used instead of worker-hours since the model measures the productivity of crews.

The image processing algorithm for analyzing and measuring crew-hours uses BGS, a color histogram, human body structure, and an optical flow (See (2) in Fig.9.).

BGS is used to recognize a moving object. Color Histogram and Human Body Structure is used to recognize a worker. Optical Flow is used to recognize the collision or overlap of workers. The number of workers in a crew and their working time is measured through this given algorithm.

The image-processing algorithm for analyzing and measuring installed work quantity uses picture images. To obtain picture images, they are extracted from the video image with a constant cycle that utilizes a work sampling technique (See (3) in Fig.9.). The algorithm for measuring installed formwork quantity uses one of the following combinations (HSV + Contour + Template Matching or HSV + Binary Pixel + Contour + Template Matching suggested by Soojung Oh, 2011), which has a higher recognition rate.

A construction work crew's unit productivity is then estimated through the data obtained from the crewhours and the installed work quantities. The estimated productivity is then integrated with the WBS code (See (4) in Fig.9.) created by the building components in order to decide the location of the work and determine the status of installation.
The data obtained from the second module goes to the third module for creating and utilizing the productivity database on Excel. Some of these are transformed into the CSV file format and are opened in Navisworks. The structural members (objects) of the BIM model are linked to the CSV file and the $4 \mathrm{D}$ simulation is run. Through this process, the productivity database of each structural member can be built (See (5) in Fig.9.). In the case of apartment construction, the same typical construction is repeated for each floor. As a result of these repetitive characteristics, it is possible to predict the information of the other floors in the apartment unit once the work information of one floor or one house unit is extracted and analyzed. This simulation of prediction can be used as a foundation for the actual work progress. The daily factors can be found using this simulation technique.

\section{Case Studies}

Two case studies of an existing construction site were performed to validate the developed system model. Case Study 1 in Fig.10. is comprised of two crews. Case Study 2 in Fig.11. is comprised of only one crew. Table 2. shows the designated colors assigned to the tasks of each case study for identifying construction work crews.

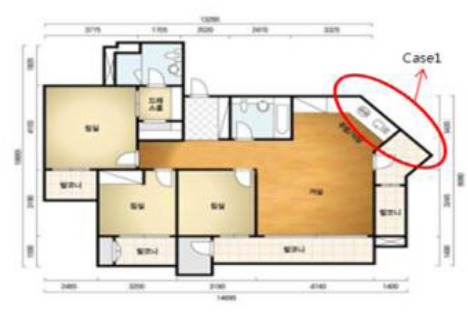

Fig.10. Floor Plan of Case Study 1

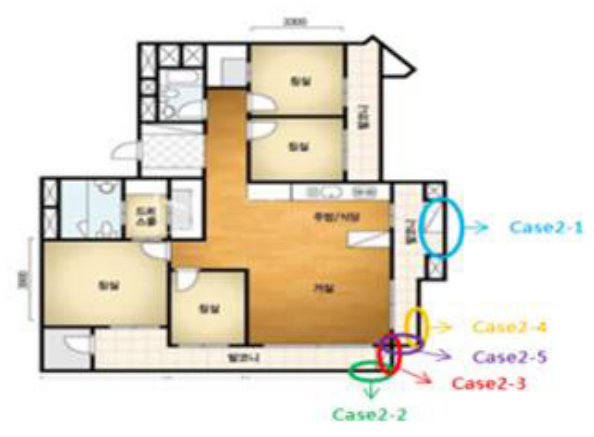

Fig.11. Floor Plan of Case Study 2

Table 2. Identification of Construction Work Crews

\begin{tabular}{c|c|c}
\hline \multirow{2}{*}{$\begin{array}{c}\text { Work item } \\
\text { description }\end{array}$} & \multicolumn{2}{|c}{ Color of helmets and vests } \\
\cline { 2 - 3 } & Case Study1 & Case Study 2 \\
\hline Carriage of form & Red & Green \\
\hline Installation of form & Blue & \\
\hline Other work & Green & Red, Blue \\
\hline
\end{tabular}




\subsection{Analysis Result of Case Study 1}

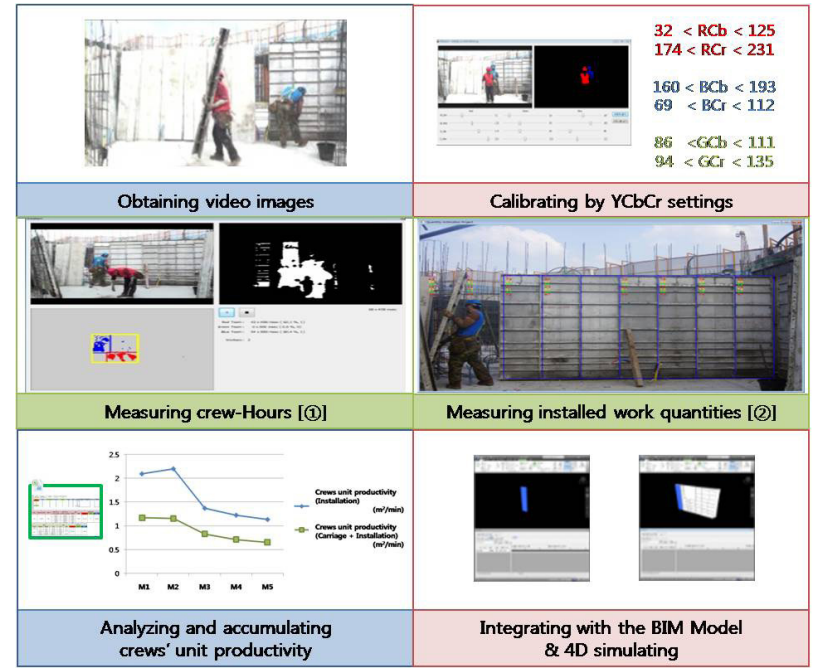

Fig.12. The Analysis Process by Case Study 1

Fig.12. depicts the process of analysis in the first case study. In this particular case study, one wall is selected to measure the productivity of the crew. After this, five $\mathrm{YCbCr}$ values are randomly chosen. An average value is then calculated and set as a threshold.

The threshold value is now set on the model and crew-hours can be analyzed. In Fig.12. [1]], the upperleft corner shows the original image; the upper-right corner shows the BGS image; the bottom-left corner shows the worker detection and collision image; and the bottom-right corner shows information such as the working time, number of workers, and time of the video.

The picture image is extracted from the analyzed crew-hour video image every $2 \mathrm{~min} 20 \mathrm{sec}$. Then, this image is analyzed with the algorithm for measuring the installed work quantity. Fig.12. [2] shows the recognition of the installed quantity. The box shows the installed formwork. The numbers in the box show the values for analyzing the image such as the recognition value of the HSV, the binary pixel, the location of the binary pixel, the contour, the template matching, the project, and the HSV + binary pixel + template matching.

Table 3. and Fig.13. show the result of analysis for Case Study 1. In Case Study 1, the formwork installation was analyzed with a cycle that had a constant measuring period. The unit productivity was calculated by dividing the sum of the cumulative crewhours from the area of the installed formwork.

The upper graph in Fig.13. only shows the productivity of formwork installation. The bottom graph in Fig.13. shows the productivity of the formwork installation as well as the carriage of the forms. The productivity in the late phase (M3, M4, \& M5) is lower than the productivity in the early phase (M1 \& M2). The difference is caused by the transport of material supplies and the varying formwork sizes in the late phase.
Table 3. The Analysis Result of Case Study 1

\begin{tabular}{|c|c|c|c|c|c|c|}
\hline \multirow[b]{2}{*}{$\begin{array}{l}\text { Measu- } \\
\text { rement }\end{array}$} & \multirow[b]{2}{*}{ Crew } & \multirow{2}{*}{$\begin{array}{c}\text { Installed } \\
\text { work } \\
\text { quantity } \\
\left(\mathrm{m}^{2}\right)\end{array}$} & \multirow[b]{2}{*}{$\begin{array}{l}\text { Crew- } \\
\text { hours } \\
\text { (min) }\end{array}$} & \multirow{2}{*}{$\begin{array}{l}\text { Cumul- } \\
\text { ative } \\
\text { crew- } \\
\text { hours } \\
\text { (min) }\end{array}$} & \multicolumn{2}{|c|}{\begin{tabular}{|c|}
$\begin{array}{c}\text { Unit productivity } \\
\left(\mathrm{m}^{2} / \mathrm{min}\right)\end{array}$ \\
\end{tabular}} \\
\hline & & & & & $\begin{array}{l}\text { Insta- } \\
\text { llation } \\
\text { (Blue) }\end{array}$ & $\begin{array}{c}\text { Carriage + } \\
\text { Installation } \\
\text { (Red + } \\
\text { Blue) }\end{array}$ \\
\hline M1 & $\begin{array}{l}\text { Red } 1 \\
\text { Blue } 1\end{array}$ & 4.86 & $\begin{array}{l}1.84 \\
2.32\end{array}$ & $\begin{array}{l}1.84 \\
2.32\end{array}$ & 2.095 & 1.166 \\
\hline M2 & $\begin{array}{l}\text { Red } 1 \\
\text { Blue 1 } \\
\end{array}$ & 9.72 & $\begin{array}{l}2.18 \\
2.10\end{array}$ & $\begin{array}{l}4.02 \\
4.42 \\
\end{array}$ & 2.199 & 1.151 \\
\hline M3 & $\begin{array}{l}\text { Red } 1 \\
\text { Blue } 3 \\
\end{array}$ & 11.34 & $\begin{array}{l}1.40 \\
3.88\end{array}$ & $\begin{array}{l}5.42 \\
8.30\end{array}$ & 1.366 & 0.826 \\
\hline M4 & $\begin{array}{l}\text { Red } 1 \\
\text { Blue 1 } \\
\end{array}$ & 12.96 & $\begin{array}{l}2.24 \\
2.33\end{array}$ & $\begin{array}{c}7.66 \\
10.63\end{array}$ & 1.219 & 0.708 \\
\hline M5 & \begin{tabular}{|l|} 
Red 1 \\
Green1 \\
Blue 1 \\
\end{tabular} & 14.58 & $\begin{array}{l}1.88 \\
1.76 \\
2.29 \\
\end{array}$ & $\begin{array}{c}9.54 \\
1.76 \\
12.92 \\
\end{array}$ & 1.128 & 0.649 \\
\hline & & 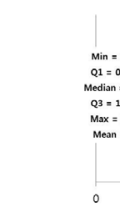 & 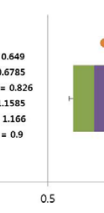 & $\begin{array}{l}-0.8 \\
0.6 \\
0.4 \\
-0.2 \\
0.5\end{array}$ & & \\
\hline
\end{tabular}

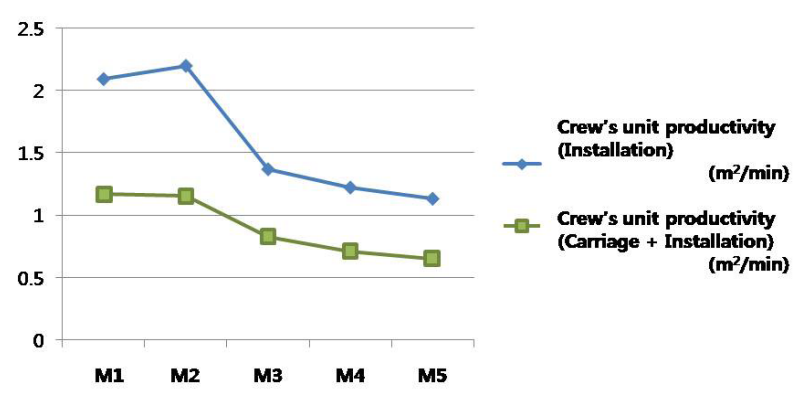

Fig.13. Crews' Unit Productivity of Case Study 1

\subsection{Analysis Result of Case Study 2}

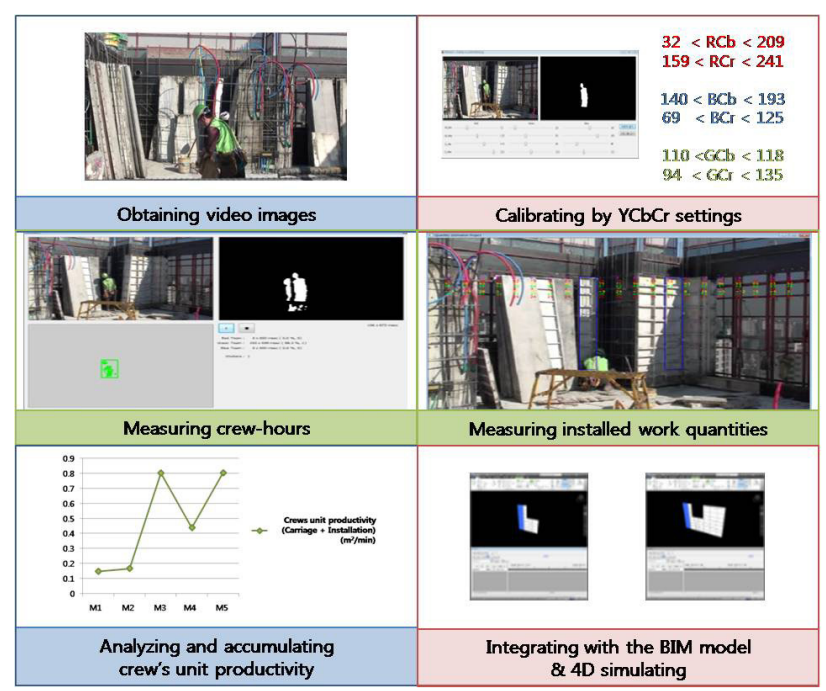

Fig.14. The Analysis Process of Case Study 2

Fig.14. depicts the process of analysis in the second case study. In Case Study 2, since one crew did all the work for the installation of formwork, the productivity was measured by the WBS that was created based on the building components. The threshold of $\mathrm{YCbCr}$ is set. 
Table 4. and Fig.15. show the result of analysis for Case Study 2. Case Study 2 was analyzed by WBS code and productivity was calculated by dividing the crew-hours from the area of installed formwork.

The productivity of Case Study 2 is much lower than the productivity of Case Study 1 due to the various openings in the wall as well as the difficulty of construction due to curved walls. There is also a difficulty in the recognition of the installed formwork because of the varying sizes.

Table 4. The Analysis Results of the Case Study 2 Analysis

\begin{tabular}{|c|c|c|c|c|}
\hline \multirow{2}{*}{$\begin{array}{l}\text { Measu- } \\
\text { rement }\end{array}$} & \multirow{2}{*}{ Crew } & \multirow{2}{*}{$\begin{array}{l}\text { Installed work } \\
\text { Quantity }\left(\mathrm{m}^{2}\right)\end{array}$} & \multirow{2}{*}{$\begin{array}{c}\text { Crew-hours } \\
\text { (min) }\end{array}$} & \multirow{2}{*}{\begin{tabular}{|c|} 
Unit productivity $\left(\mathrm{m}^{2} / \mathrm{min}\right)$ \\
Carriage + Installation(Green)
\end{tabular}} \\
\hline & & & & \\
\hline M1 & Green 1 & 4.05 & 27.35 & 0.148 \\
\hline M2 & $\begin{array}{c}\text { Red 1 } \\
\text { Green1 } \\
\text { Blue 1 }\end{array}$ & 1.62 & $\begin{array}{l}2.56 \\
9.66 \\
0.05\end{array}$ & 0.168 \\
\hline M3 & Green 1 & 6.48 & 8.07 & 0.803 \\
\hline M4 & Green1 & 2.43 & 5.53 & 0.439 \\
\hline M5 & Green1 & 4.86 & 6.04 & 0.804 \\
\hline & & 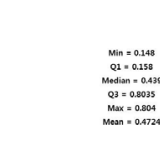 & 0.5 & {$\left[\begin{array}{l}12 \\
-1 \\
08 \\
06 \\
06 \\
-04 \\
02 \\
0.0 \\
10\end{array}\right.$} \\
\hline
\end{tabular}

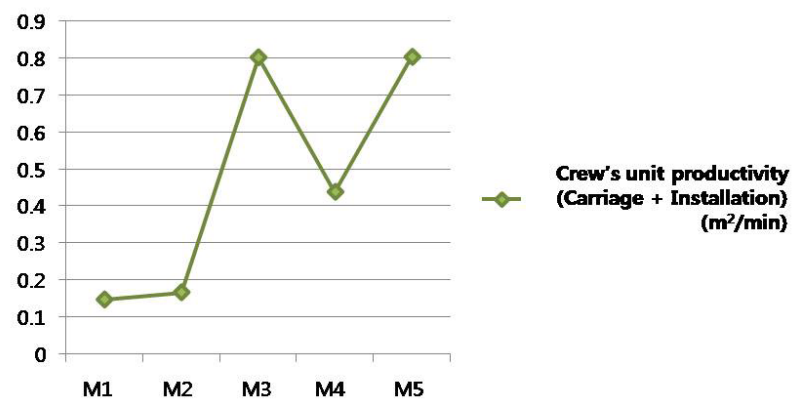

Fig.15. Crew's Unit Productivity of Case Study 2

\section{Conclusion}

This study proposed a system model based on image processing, which automatically measures and analyses the productivity data of construction work crews. Two previously developed algorithms were adopted and modified to measure installed quantity and crew-hours. A correction algorithm for improving the recognition rate was additionally introduced. Work sampling and video editing were used to measure and analyze the productivity data and statistical methods were used to handle outliers. Advanced construction productivity data and its utilization method are proposed using the integration of the BIM Model. The developed model is applied to a real construction site and thus validates its feasibility and potential through the implementation of two case studies.

The proposed system model can recognize the workers and materials on a construction site. It can also measure and analyze the productivity of the crew, which is then processed and integrated with the objects of the BIM Model to accumulate and utilize the data continuously. This reliable data can be further used for similar projects in the future. Based on the results of this study, image-processing technology is expected to expand its application to various other types of construction work. It will effectively help many aspects of construction management.

\section{Acknowledgments}

This research was supported by the Basic Science Research Program through the National Research Foundation of Korea (NRF) funded by the Ministry of Education, Science and Technology(2011-0005837).

\section{References}

1) Escorcia, V. (2012) Automated vision-based recognition of construction worker actions for building interior construction operations using RGBD cameras. Construction Research Congress 2012: Construction Challenges in a Flat World, pp.879-888.

2) Gong, J. (2009) An intelligent video computing method for automated productivity analysis of cyclic construction operations. Computing in Civil Engineering(2009), pp.64-73.

3) Gong, J. (2011) Learning and classifying motions of construction workers and equipment using bag of video feature words and bayesian learning methods. Computing in Civil Engineering(2011), pp.274-281.

4) Kekre, H.B. (2013) Performance evaluation of bins approach in $\mathrm{YCbCr}$ color space with and without scaling. International Journal of Soft Computing and Engineering, 3 (3), pp.203-210.

5) Kim, S.B. (2008) A study on the development strategies of construction productivity analysis system based on web \& OLAP. Journal of the Architectural Institute of Korea, 24 (5), pp.173-184.

6) Lee, C.K. (2011) The application of image processing technology for recognizing and distinguishing construction workers. Build SMART Construction IT \& BIM User Conference 2011, pp.87-88.

7) Lee, H.J. (2006) Collection and utilization of the construction productivity data and the influence factors using information technology. Proceedings of the 2006 Korea Institute of Construction Engineering and Management, pp.548-553.

8) Oh, S.J. (2011) A study of image processing application for measurement of form installed on the construction site. Build SMART Construction IT \& BIM User Conference 2011, pp.97-98.

9) Ordonez, C. (2011) Detection of outliers in GPS measurements by using functional-data analysis. Journal of Surveying Engineering, 137 (4), pp.150-155.

10) Park, J.D. (2011) BIM-based parametric design methodology for modernized Korean traditional buildings. Journal of Asian Architecture and Building Engineering 2011, pp.327-334.

11) Park, M.W. (2012) Detection of construction workers in video frames for automatic initialization of vision trackers. Construction Research Congress 2012: Construction Challenges in a Flat World. pp.940-949.

12) Peddy, A. (2009) Development of human pose analyzing algorithms for the determination of construction productivity. Construction Research Congress 2009: Building a Sustainable Future, pp.11-20.

13) TharinduWeerasinghe, I.P. (2012) Application of Microsoft Kinect sensor for tracking construction workers. Construction Research Congress 2012: Construction Challenges in a Flat World, pp.858867.

14) Woo, K.B. (2007) The development of a construction productivity prediction model based on data mining. Proceedings of the 2007 Korea Institute of Construction Engineering and Management, pp.813-818. 